\title{
Influence of the Family Socialization on the Formation of Gender Features of Modern Teenagers
}

\author{
Aigul R. Gallyamova
}

Kazan (Volga region) Federal University, Kazan, Russia

Email: aigul_diss@mail.ru

Svetlana V. Smirnova

Amur State University, Blagoveschensk, Russia

Tatyana M. Kozhanova

Marina V. Emelyanova

Antonina A. Budantsova

Chuvash State Pedagogical University named after I.Y. Yakovlev, Cheboksary, Russia

Ekaterina I. Sokolova

Nelli G. Atayanz

Russian State Social University, Moscow, Russia

\section{Doi:10.5901/mjss.2015.v6n2s3p71}

\section{Abstract}

The relevance of the investigated problem is due to insufficient knowledge about the impact of parent-child relationship features on the development of the adequate teenager gender identity. The purpose of the article is to study the effect of the family socialization on the formation of gender features of modern teenagers. The leading approach to the study of this problem is the system-activity approach. In the course of empirical study it was found that the formation of masculine features of modern teenagers during the family socialization is associated with a positive attitude on the part of the father, and the formation of feminine traits is due to a positive attitude on the part of the mother and too rigid and inconsistent attitude on the part of the father. The article's materials may be useful for psychologists, teaching staff, social workers.

Keywords: socialization; parent-child relationships; gender features; femininity; masculinity; teenagers.

\section{Introduction}

\subsection{Background}

One of the main problems of modern psychology gender theory is the question of gender socialization and identification in terms of transformation and crisis of Russian society. During the gender socialization of teenagers, i.e. in the process of acquiring the rules, values, attitudes, norms of masculine or feminine behavior there reveals a complex multidimensional system, or rather, the composition of socio-cultural multi-level interactions.

Due to changes in the socio-cultural situation in Russia, transformation of values of the Russians, including teenagers, deep social crisis affecting the family, we can talk about the crisis of gender socialization of teenagers.

The gender socialization, as a part of the overall process of socio-cultural reproduction of society, is one of the least studied problems in psychology. This state of affairs seems reasonable, since 1) the complexity of the problem of gender socialization is connected with biopsychosocial nature of gender and therefore requires the inter-disciplinary biopsycho-sociological approach; 2) the genderology, as a relatively independent area of scientific knowledge, appeared only in the 70s of the twentieth century; 3 ) there has not yet developed the research methodology of this phenomenon. 
However, social transformation, affecting all spheres of modern life, with a new force has defined the contradictory position of the genders in the private and public spheres, has had a marked impact on a marriage and a family, relations between spouses, parents and children, thereby actualizing the problem of taking individuals' gender roles (gender socialization) exactly in a transitional society (Legenina, 2004)

In childhood and adolescence the family is one of the main institutions of socialization. Namely under the influence of relations on the part of parents it is forming the identity of a teenager. The modern family is a family that lives in the new socio-economic conditions and is one of the most flexible, changeable social groups (Smirnova, 2005). On the one hand, just through it, the preservation and continuity of classical gender stereotypes and attitudes are ensured, and on the other hand, it is the family that becomes for the child a conductor of new trends that are reflected in the minds of the spouses as their value orientations, needs, life plans, relationships between genders. It is namely in the family a new understanding of the place and role of men and women in modern world is formed, a gender moral is changing, subcultural differentiation of gender and gender-role identity is transforming. (Shabanov, Shelehov, Ruban , 2009). Under the influence of new trends in the development of society there are taking place the changes in the attitude of parents to children, in the approaches to children upbringing in the family, all these factors also influence the gender socialization features of modern teenagers.

Recent years scientific studies show that modern teenagers often have an inadequate perception of gender roles and related behavioral distortions (Ponewag, 2007). In this regard, it is actualizing the need to study the effect of family socialization on the formation of teenagers' gender peculiarities to develop further correction of psycho-pedagogical programs for working with teenagers and their families, as well as to optimize the educational process both in families and educational institutions.

\subsection{Explore Importance of the Problem}

Gender socialization is the process of assimilation by the individual the gender cultural system of the society in which he/she lives, it is a kind of designing differences between the genders. The main socializing factors (agents) are social groups and contexts - family, education institutions, peers, media, clubs, churches, and others. In the works of native psychologists is generally considered a small range of issues relating to gender problems, namely: the emergence and the development of gender studies in psychology, peculiarities of the organization and research in the field of gender, meaningful characteristics of gender stereotypes (Kletsina, 2003).

One of the main areas of gender studies in psychology is the actual gender study, which is conducted within the framework of social and psychological direction. The theoretical basis for this research is the gender approach that focuses on how specific behavior and roles of gender acquire a gender tint, on appearance of gender differences in the work and reflection of gender values and benefits by social structures (Filatova, 2009).

The modern social situation is that children are surrounded by a lot of women and female, the child has relatively little opportunity for proper masculine manifestations. The gender-role socialization in its present form leads to paradoxical results: as if boys are pushed to the passivity or out social activity, girls, on the contrary - to hyperactivity and dominance. At the same time they have to live in a society mainly oriented to traditional gender-role standards (Rimarev, 2006). Inadequate formedness of gender roles, gender identity crisis is a problem of not a single personality, but a state of psychological distress, which is characteristic for a significant part of both men and women as representatives of the gender groups. Consistent gender identity causes positive self-identity as a representative of a particular gender and the subject of gender relations. Contradictions expressed in the structure of gender identity predetermine the negative attitude of the person to oneself, that provokes a state of intrapersonal conflict and crisis manifestations (Stepanova, 2007).

The central factor in the psychological development of adolescence, its the most important new formation is the establishing of a new level of consciousness, the change in a self-concept determined by the desire to understand oneself, one's capabilities and features such as combining teenagers with other people, groups of people and distinguishing from them, making them unique. This is related to the sharp fluctuations in the relation to oneself, the instability of self-esteem (Elkonin, 2004). During this period inadequately formed perception of one's gender identity may have a bad influence on the successful formation of the teenager's personality, may lead to violations of his/her socialization.

\subsection{Status of a problem}

The studies on gender socialization of teenagers were carried out mainly within the framework of psycho-physiological 
paradigm during the second half of the XIX-XX centuries. For physiologists the puberty is a constant anthropological characteristic of the person. However, in terms of socio-psychology the phenomenon of "adolescence", "juvenile" from the time of (Mid, 1988) is not a universally-historical category, but a theoretical construct that reflects the realities of modern society. The puberty has been extensively studied not only by physiologists, but also by psychologists and psychoanalysts - (Freud, 1921, Piaget, 2003). There has been paid a special attention to puberty in the history of the personality development, as well as to psychosexual development and changes in the intellectual sphere.

The development of the basic ideas about the structure and functions of gender identity goes back to the classical foreign works and theories of identity and has been studied many scientifics. Thanks to modern research, masculinity and femininity are considered as independent variables, different combinations of which have different effects on social adaptation of men and women (Peregudina, 2011). The researchers pointed out that masculinity and femininity are not opposed to each other, that a person can have both masculine and feminine traits, and believe that it is desirable for a person to be androgynous, so that to incorporate the best of both gender roles (Stolyarchuk, 2012).

The role of the family is analyzed in many studies devoted to role gender or gender socialization (Introduction to Gender Studies, 2001). In the family during the process of interiorization and identification the assimilation of gender roles of society is happening, corresponding to the dominant gender order. The special role occupies the mother as the leading agent of gender socialization (Bern, 2001), and the role of the father in the research remains a "white spot", with the exception of some works demonstrating that more emancipated ("non-traditional", achieving success ) girls grow in families where fathers pay attention to the up-brining of their children (Kletsina, 2004).

\subsection{The research hypothesis}

The formation of masculine traits of modern teenagers in the family socialization is associated with a positive attitude on the part of the father, and the formation of feminine traits is due to a positive attitude on the part of the mother and too rigid and inconsistent attitude on the part of the father.

\section{Materials and Methods}

\subsection{The objectives of the research}

In the study, the following objectives have been solving: 1) the theoretical analysis of the scientific literature on the research topic; 2) the selection of psychodiagnostic tools, methodic of the research; 3) the testing of the respondents; 4) the data processing by methods of mathematical statistics; 5) analysis of the data, their theoretical conceptualization, formulation of conclusions.

\subsection{Theoretical and empirical methods.}

The selected research methodology, the basic foundation of which are the socio-psychological and gender approaches, have led to the choice of research methods and methodic. In the course of studies there are used the methods of empirical and theoretical levels. The first includes social and psychological testing. Methods of the theoretical level are the analysis, synthesis, comparison, generalization of the results of empirical research. When processing the results of the research, there are used statistical treatment (analysis of the reliability of the difference of average indicators (Student's T-test) and two-way correlation analysis (Pearson correlation coefficient).

For the diagnosis of psychological gender and determination the degree of personality's androgyny, masculinity and femininity it is used the gender roles questionnaire S.Bem (Bem, 2004). To study the effect of parents' attitude on the formation of gender identity in the process of socialization there is used the ADOR questionnaire aimed at examining the attitudes, behavior and methods of parents' up-brining as they are seen by their children in their teens (Wasserman, Gorkovskaya, Romitsyna, 2004).

\subsection{The basis of the research}

The study has involved 178 teenagers aged 13-17 years (students of municipal budgetary general education institution "Dzhalil secondary school №1 with advanced study of some subjects"). There are 96 girls and 82 boys. There are identified masculine features for $33(34.4 \%)$ girls, androgynous - for 41 (42.7\%), and the feminine - for $22(22.9 \%)$. There are identified masculine features for $16(19.5 \%)$ boys, androgynous - for $43(52.4 \%)$, and the feminine - for 23 (28.1\%). 
Therefore, we can say that modern teenagers actually have gender identity and gender socialization disorder.

\subsection{The stages of the research}

The research has been conducted in three stages:

Stage I - the study of the problem of gender socialization of modern teenagers, analysis of the causes and discovery of the factors that influence the formation of gender identity features; - definition of the goal, objectives and working hypothesis of the research.

Stage II - familiarization and review of scientific literature on the research problem; collecting statistical and analytical material for justification of the proposed hypothesis.

Stage III - analysis and systematization of the data, formulation of conclusions and recommendations, presentation of research results in the form of the article.

\section{Results}

\subsection{Special features of the impact on gender socialization of teenagers, attitude on the part of the mother}

The results of the research have showed that modern teenagers with feminine features on the part of the mother have a high level of positive interest and reduced hostility. Teenagers with masculine and androgynous features attitude on the part of the mother are about the same (Table 1).

Table 1. The features of the attitude on the part of the mother (Student's T-test)

\begin{tabular}{|l|c|c|c|c|c|c|}
\hline & \multicolumn{2}{|c|}{ masculinity/ androgyny } & \multicolumn{2}{c|}{ masculinity/ femininity } & \multicolumn{2}{c|}{ femininity/ androgyny } \\
\hline & $\mathrm{T}$ & $\mathrm{p}$ & $\mathrm{T}$ & $\mathrm{p}$ & $\mathrm{T}$ & $\mathrm{p}$ \\
\hline Mother positive interest & -0.522 & 0.606 & $-2.402^{*}$ & 0.049 & 1.751 & 0.090 \\
\hline Mother directivity & -1.228 & 0.230 & -0.234 & 0.821 & -1.369 & 0.181 \\
\hline Mother hostility & -0.278 & 0.783 & 1.204 & 0.263 & $-2.068^{\star}$ & 0.047 \\
\hline Mother autonomy & -0.151 & 0.881 & -0.499 & 0.631 & 0.705 & 0.486 \\
\hline Mother inconsistency & -1.383 & 0.178 & -0.718 & 0.493 & -0.852 & 0.401 \\
\hline Mother intimacy & -0.139 & 0.890 & -1.629 & 0.142 & $2.107^{\star}$ & 0.043 \\
\hline Mother criticism & -0.710 & 0.484 & 0.165 & 0.873 & -1.300 & 0.203 \\
\hline
\end{tabular}

There have been established significant differences of averages indicators in the groups of masculine and feminine teenagers on a scale of positive interest on the part of the mother $(T=-2.402$ at $p=0.049)$. In groups of feminine and androgynous teenagers have been established significant differences in average indicators on a scale of hostility $(T=-$ 2.068 at $p=0.047)$ and intimacy on the part of the mother $(T=2.107 p=0.043)$.

The results of correlation analysis of interrelation of attitude on the part of the mother on the formation of modern teenagers' masculinity and femininity using the Pearson correlation coefficient are shown in Table 2.

Table 2. Interrelation of attitude on the part of the mother on the formation of modern teenagers' masculinity and femininity (Pearson correlation coefficient)

\begin{tabular}{|l|c|c|}
\hline & Masculinity & Femininity \\
\hline Mother positive interest & 0.092 & $0.628^{* *}$ \\
\hline Mother directivity & 0.119 & 0.092 \\
\hline Mother hostility & -0.021 & $-0.364^{*}$ \\
\hline Mother autonomy & 0.081 & 0.211 \\
\hline Mother inconsistency & 0.028 & 0.096 \\
\hline Mother intimacy & 0.062 & $0.543^{* *}$ \\
\hline Mother criticism & 0.032 & -0.060 \\
\hline
\end{tabular}

**. Correlation is significant at the 0.01 level (two-sided).

*. Correlation is significant at the 0.05 level (two-sided).

Correlation analysis has revealed that the attitude on the part of the mother is not associated with the formation of 
masculine features, but related to the formation of feminine traits. And the feminine traits of modern teenagers form stronger with a positive interest $(r=0.628$ at $r \leq 0.01)$ and intimacy $(r=0.543$ at $r \leq 0.01)$ on the part of the mother, and hostility on the part of the mother influences negatively on their formation (when $r=-0.364 r \leq 0.05$ ).

\subsection{Special features of the impact on gender socialization of teenagers, attitude on the part of the mother}

On the ground of the conducted study it has been found that directivity and inconsistency are prevalent in teenagers with feminine traits with an attitude on the part of their father, and positive interest are prevalent in teenagers with masculine traits (Table 3).

Table 3. The features of the attitude on the part of the father (Student's T-test)

\begin{tabular}{|l|c|c|c|c|c|c|}
\hline & \multicolumn{2}{|c|}{ masculinity/ androgyny } & \multicolumn{2}{c|}{ masculinity/ femininity } & \multicolumn{2}{c|}{ femininity/ androgyny } \\
\hline & $\mathrm{T}$ & $\mathrm{p}$ & $\mathrm{T}$ & $\mathrm{p}$ & $\mathrm{T}$ & $\mathrm{p}$ \\
\hline Father positive interest & -1.100 & 0.280 & -0.412 & 0.689 & -0.886 & 0.382 \\
\hline Father directivity & -0.843 & 0.406 & 0.383 & 0.710 & -1.718 & 0.095 \\
\hline Father hostility & -1.843 & 0.076 & -1.871 & 0.091 & 0.562 & 0.578 \\
\hline Father autonomy & $-2.503^{\star}$ & 0.018 & -1.213 & 0.253 & -1.105 & 0.277 \\
\hline Father inconsistency & -1.672 & 0.105 & $-3.234^{*}$ & 0.009 & $2.357^{*}$ & 0.029 \\
\hline Father intimacy & 0.322 & 0.750 & 0.905 & 0.387 & -1.025 & 0.313 \\
\hline Father criticism & 1.413 & 0.168 & $2.882^{\star}$ & 0.016 & -1.181 & 0.246 \\
\hline
\end{tabular}

There have been established significant differences of averages indicators in the groups of masculine and androgynous teenagers on a scale of autonomy $(T=-2.503$ at $p=0.018)$, the groups of masculine and feminine teenagers on the scale of inconsistency $(T=-3.234$ at $p=0.009)$ and criticism $(T=2.882 p=0.016)$ and groups of feminine and androgynous teenagers on a scale of inconsistency $(T=2.357 p=0.029)$.

The results of correlation analysis of interrelation of attitude on the part of the father on the formation of modern teenagers' masculinity and femininity using the Pearson correlation coefficient are shown in Table 4.

Table 4. Interrelation of attitude on the part of the father on the formation of modern teenagers' masculinity and femininity (Pearson correlation coefficient)

\begin{tabular}{|l|c|c|}
\hline & Masculinity & Femininity \\
\hline Father Positive Interest & $0.413^{* *}$ & 0.059 \\
\hline Father Directivity & -0.132 & $0.369^{*}$ \\
\hline Father Hostility & 0.123 & 0.305 \\
\hline Father Autonomy & -0.025 & 0.020 \\
\hline Father Inconsistency & 0.136 & $0.462^{* *}$ \\
\hline Father Intimacy & 0.011 & -0.156 \\
\hline Father Criticism & -0.155 & -0.313 \\
\hline$* \star$ & Correlation is significant at the 0.01 level (two-sided) \\
\hline *. Correlation is significant at the 0.05 level (two-sided) \\
\hline
\end{tabular}

Correlation analysis has revealed that the attitude on the part of the father is associated with the formation of both masculine and feminine traits. Thus, the positive interest from the part of the father is positively connected with the formation of masculinity $(r=0.413$ at $r \leq 0.01)$, and directivity and inconsistency are positively connected with the formation of femininity $(r=0.369$ at $r \leq 0.05$ and $r=0.462$ at $r \leq 0.01)$.

\section{Discussions}

The study found that the more the mother's attitude manifests such traits as hyper protection, the desire to satisfy every wish, an attitude to a teenager as a young child who requires constant attention, care, assistance, who is not enough able to do anything, a limitation of teenager's autonomy, the more the teenagers' feminine traits are formed. If the behavior of the mother manifests traits such as suspicious attitude to a family environment and distance in relation to its members (particularly children), the self orientation of mothers, aggressiveness, emotional coldness and excessive strictness in 
dealing with a teenager, so the formation of feminine traits is declining, but at the same time the masculine traits are not forming.

The obtained data show that the teenagers' masculinity is rising if a father tries to win their affection and reverence of father's authority primarily through mutual trust, common sense. In this case, the behavior of the father demonstrates self-confidence, confidence that not strictness but attention to a teenager, warmth and open relationships between a father and a child are a manifestation of genuine interest. A clear understanding the boundaries of what is possible and what is not exists in case of warm and friendly relations dominance. Father's prohibitions act in this case only on the background of paternal love. This attitude creates the teenager's self-confidence in his/her abilities, the ability to find ways out of different situations without any fair to ask for advice, independence.

If in its attitude to a child or a teenager a father demonstrates his strong will of a man, who is always ready to show a child his/her place both in the world and in the family, makes to obey the accepted norms and rules, but behaves unpredictably, doesn't support his behavior by these rules and values, so it promotes the formation of feminine traits such as uncertainty and weakness.

\section{Conclusion}

Presented in the article the results of the research let us make the conclusion that the formation of modern teenagers masculine traits in the family socialization is associated with a positive attitude on the part of the father, and the formation of feminine traits is caused by a positive attitude on the part of the mother and too rigid and inconsistent attitude on the part of the father. Thus, the goal of the research is reached, the hypothesis is confirmed.

\section{References}

Bern Sh. (2001). Gender psychology. St. Petersburg. PRIME-EUROSIGN.

By Page (2004). Gender lenses. Transformation of views of a problem of an inequality of floors. Moscow.

Elkonin D.B. (2004). Age and specific features of younger teenagers. Moscow. Progress.

Filatova A.F (2009). Sexual distinctions in formation of character of the teenager. Moscow.

Freud. Z. (1921). Psychology of masses and analysis of the Ego. Vienna.

Introduction to gender researches. (2001). Kharkov. HTsGI. St. Petersburg.

Kletsina I. of page (2004). Psychology of the gender relations: Theory and practice. St. Petersburg.

Kletsina I.S. (2003). From floor psychology - to gender researches. Psychology questions. 1 (43-52).

Legenina T.B. (2004). Gender socialization in a family: sociocultural aspect. Stavropol.

Mid. M. (1988). Culture and world of the childhood. Moscow.

Peregudina V.A. (2011). Formation of male and female gender identity in the age range from the senior preschool to youthful age. Tula.

Piaget J. (2003). Intelligence psychology. Moscow.

Ponewag E.V. (2007). Psychological features of socialization of the senior teenagers in group of contemporaries. Moscow.

Rymarev N. Yu. (2006). Personal features of teenagers with various gender identity. Krasnodar.

Shabanov L.V., Shelehov I.L., Ruban N.N. (2009). Sex and gender identity of teenagers from families of various type. Bulletin of Tomsk state pedagogical university. 8 (100-103).

Smirnova A.V. (2005). Gender socialization at comprehensive school. N. Novgorod.

Stepanova L.G. (2007). The intra personal gender conflict in the context of the family relations. A family in Russia. 4 (67-76).

Stolyarchuk L.I. (2012). Gender approach in the conditions of continuous education. News of the Volgograd state pedagogical university. 4 (33-37).

Wasserman L.I., Gorky I.A., Romitsyna E.E. (2004). Parents teenager's eyes: psychological diagnostics in medico-student teaching. St. Petersburg. Speech. 